\title{
Hand Foot and Mouth Disease Like Illness in Office Practice: Correspondence
}

To the Editor: The publications on Hand Foot and Mouth like disease is very interesting [1]. Ganga reported the experience on an outbreak and noted that "Early clinical diagnosis of Hand Foot and Mouth disease (HFMD) is required for monitoring and prevention of its spread [1]." There is no doubt that early diagnosis is useful for management of any disease outbreak. However, the important consideration is on the accuracy of the diagnosis. The clinical diagnosis of Hand Foot and Mouth disease might be possible but it might lack in accuracy. In the another publication, Zhou et al. mentioned for the advantage of laboratory diagnosis in Hand Foot and Mouth disease. Zhou et al. also mentioned about the usefulness of investigations in making the prognosis [2]. In fact, there are many similar tropical diseases that can manifest and mimic Hand Foot and Mouth disease. The clinical management of other tropical diseases might be different. In addition, lack of definitive diagnosis can lead to lack of epidemiology data which is useful for planning the disease control in the future. As noted by Hyeon et al., "surveillance of enterovirus infections such as this study provides may assist with evaluating the need to research and develop treatments for infections caused by virulent human EV genotypes [3]."

\author{
Viroj Wiwanitkit \\ Surindra Rajabhat University, Surin, Thailand \\ E-mail:wviroj@yahoo.com
}

3. Hyeon JY, Hwang S, Kim H, et al. Accuracy of diagnostic methods and surveillance sensitivity for human enterovirus, South Korea, 1999-2011. Emerg Infect Dis. 2013;19:1268-75.

\section{Author's Reply}

To the Editor: Thank you very much for the interest documented on my article "Hand Foot and Mouth disease like illness in office practice" [1]. These children were treated in a resource limited semi urban set-up where virological confirmations or advanced blood investigations are not feasible. Due to religious myths, getting parents' consent for investigation is difficult in childhood skin lesions.

It is agreed that accurate diagnosis is possible with virological confirmation. The clinical data was published for the following reasons:

1. To create awareness about this entity among primary care physicians who take care of children.

2. With the probable clinical diagnosis the children can be meticulously followed up for complications.

3. To sensitize the parents regarding the need for treatment and follow-up.

The above steps are mandatory to reduce the mortality.

N. Ganga

Department of Pediatrics, Vinayaka Missions Medical College, Karaikal, Puducherry, India. E-mail: gangs.mythila@gmail.com

\section{Reference}

1. Ganga N. Hand Foot and Mouth disease like illness in office practice. Indian J Pediatr. 2016 Dec 12. [Epub ahead of print] doi:10.1007/ s12098-016-2271-3. 